Research Paper

\title{
More attention should be paid to adult gastric cancer patients younger than 35 years old: extremely poor prognosis was found
}

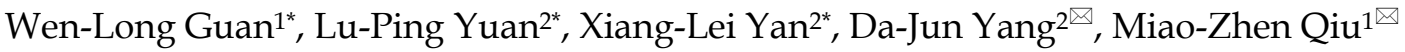 \\ 1. Department of Medical Oncology, Sun Yat-Sen University Cancer Center; State Key Laboratory of Oncology in South China; Collaborative Innovation \\ Center for Cancer Medicine, Guangzhou, China. \\ 2. Department of Experimental Research, Sun Yat-Sen University Cancer Center; State Key Laboratory of Oncology in South China; Collaborative Innovation \\ Center for Cancer Medicine, Guangzhou, China.
}

*Wen-Long Guan, Lu-Ping Yuan and Xiang-Lei Yan contributed equally to the manuscript.

$\square$ Corresponding authors: Dajun Yang, MD, PhD, Department of Experimental Research, Sun Yat-Sen University Cancer Center; State Key Laboratory of Oncology in South China; Collaborative Innovation Center for Cancer Medicine, 651 Dongfeng Road East, Guangzhou 510060, China. Tel.: +86 20 8734 2285; Fax: +86 208734 2285; E-mail: yangdj@sysucc.org.cn. Dr. Miao-Zhen Qiu, Department of Medical Oncology, Sun Yat-Sen University Cancer Center; State Key Laboratory of Oncology in South China; Collaborative Innovation Center for Cancer Medicine, 651 Dongfeng Road East, Guangzhou 510060, China. Tel: +86-20-8734 2490; Fax: +86-20-8734 3295; E-mail: qiumzh@sysucc.org.cn

( $)$ Ivyspring International Publisher. This is an open access article distributed under the terms of the Creative Commons Attribution (CC BY-NC) license (https://creativecommons.org/licenses/by-nc/4.0/). See http://ivyspring.com/terms for full terms and conditions.

Received: 2018.05.28; Accepted: 2018.12.05; Published: 2019.01.01

\begin{abstract}
Purpose: Several studies have reported controversial results about prognosis of gastric cancer in young age patients. The difference may partially result from variable definitions of young age. The aim of this study was to find out the relation between age and prognosis of gastric cancer patients, and to analyze the clinicopathological features and prognostic factors in young gastric cancer patients.

Methods: Data queried for this analysis included GC patients from the Surveillance, Epidemiology, and End Results Program database from 1973 to 2014. Gastric cancer patients $(N=79,505)$ diagnosed with an age $\geq 18$ were included. By combining patients with similar prognosis, we figured out 3 cutoff values of age, 35 years old, 65 years old and 75 years old. We divided patients into 4 groups: young age patients: 18-34 years; middle-age patients: 35-64 years; elderly patients: 65-74 years; extremely elderly patients: $>74$ years. GC patients from Sun Yat-sen University Cancer Center (SYSUCC) were used as external validation data.

Results: The clinicopathological features of young age gastric cancer patients included: poor-differentiated, diffuse type of cancer, and advanced stage at diagnosis. The median survival of patients $<35$ years old was significantly lower than middle-age patients (35-64 years) and elderly patients (65-74 years) $(12$ months vs. 15 and 16 months, respectively, both $p<0.001)$. Location of tumor, ethnicity, tumor size, surgery and TNM stage were independent prognostic factors by multivariate analysis in young patients. The poor prognosis for young patients remained valid in the SYSUCC database.

Conclusions: Our results demonstrated that gastric cancer patients $<35$ years old had an extremely poor prognosis. Early detection of gastric cancer is of paramount importance in young age people.
\end{abstract}

Key words: Age, Clinic-pathologic features, Gastric cancer, Prognosis, Young, Clinic-pathologic features

\section{Introduction}

Gastric cancer (GC) is the fourth most common

cancer and the second leading cause of cancer-related 
death in the world (1). Although GC mostly occurs in the 50-70 age groups and the overall incidence of GC has declined in last decade, the incidence rate in younger patients has increased $(2,3)$. Compared to the older age group, the clinicopathological features and prognosis of young GC patients remain controversial. Some studies have revealed that the prognosis of GC is worse in younger patients due to delayed diagnosis or more advanced stage (4-6). However, other studies state that the prognosis in the young patients is comparable to the older patients (7-9), or even better $(10,11)$. The controversy findings may result from many reasons, including sample size, ethnicity, and different definitions of young age group. Most literatures defined young age as below 40 or 45 years $(5-7,9,12-19)$, while others used 30, 50, 60 or even $70(4,8,10,11,20-23)$. The difference of cut-off value for ages may lead to different outcomes of analysis. Besides, in clinical practice, we found that the proportion of extremely young patients (20-30 years old) was increasing, and prognosis of this age group was poor. To investigate the association between age and prognosis, we reviewed the epidemiologic and clinicopathological characteristics of GC patients based on Surveillance, Epidemiology, and End Results (SEER) population-based data.

\section{Methods}

\section{Database}

The SEER database is the largest publicly available cancer dataset. It is a population-based cancer registry across several disparate geographic regions. The SEER research data include cancer incidence and prevalence as well as demographic information tabulated by age, sex, race / ethnicity, year of diagnosis and Tumor-Node-Metastasis (TNM) stage. The exact dataset we used for this analysis was SEER Program (www.seer.cancer.gov) Research Data (1973-2014), National Cancer Institute, DCCPS, Surveillance Research Program, Surveillance Systems Branch, based on the November 2016 submission.

Another cohort from the Sun Yat-sen University Cancer Center (SYSUCC) was used as external validation data. It included all the gastric adenocarcinoma cancer patients who received therapy and had full record of follow-up in SYSUCC during 2000 and 2013 (Supplementary table 1). The study protocol for the Chinese cohort was approved by the independent Ethics Committees at SYSUCC.

\section{Outcome variables}

Variable definitions information on age at diagnosis, sex, year of diagnosis, race/ethnicity, primary site, tumor grade and differentiation, histology, lymph node involvement, AJCC $7^{\text {th }}$ TNM stage, insurance status and overall survival were coded and available in SEER database.

The primary site was defined by the following International Classification of Diseases for Oncology (ICD-O-2) codes: C16.0-C16.9. Cardia, (C16.0), fundus (C16.1), body (C16.2), antrum (C16.3), pylorus (C16.4), lesser curvature (C16.5), greater curvature (C16.6), overlapping lesion (C16.7) and stomach, NOS (C16.9).

Grade and differentiated was defined by the following ICD-O-2 codes; well differentiated (Code 1), moderate differentiated (Code 2), poorly differentiated (Code 3) and undifferentiated (Code 4).

Histological types were defined by the following ICD-O-3 codes: 8140 to 8147,8210 to 8211,8220 to 8221 , and 8260 to 8263 for adenocarcinoma, 8480 and 8481 for mucinous adenocarcinoma, and 8490 for Signet ring cell carcinoma.

For the Race/Ethnicity, we reclassified the patients into 5 groups: "Caucasian", "African American", "Asian", "Others" and "Unknown".

\section{Patient Population}

The study population was based on the SEER cancer registry. We restricted eligibility to patients with gastric adenocarcinoma (including mucinous adenocarcinoma and signet ring cell carcinoma) from 1973 to 2014 with an age $\geq 18$. We excluded cases without follow-up records (survival time code of 0 months).

\section{Statistical Methods}

The patients' demographic and tumor characteristics were summarized with descriptive statistics. Comparisons of categorical variables were performed using the Chi square test, and continuous variables were compared using Student's $t$ test. The primary endpoint of this study was 5-year cause specific survival (CSS), which was calculated from the date of diagnosis to the date of cancer specific death. Deaths attributed to gastric cancer were treated as events and deaths from other causes were treated as censored observations. Survival function estimation and comparison among different variables were performed using Kaplan-Meier estimates and the log-rank test. The independence of the prognostic factors was adjusted for other known factors including age at diagnosis and tumor stage. All of statistical analyses were performed using the Intercooled Stata 13.0 (Stata Corporation, College Station, TX). Statistical significance was set at two-sided $\mathrm{P}<0.05$.

\section{Informed consent and Protection of Human Subjects}

This study with SEER data was deemed exempt from institutional review board approval by Sun 
Yat-sen University Cancer Center and informed consent was waived. The study protocol for the Chinese cohort was approved by the independent Ethics Committees at SYSUCC.

\section{Results}

\section{Cut-off points of age groups}

We identified 79,505 GC patients diagnosed between 1973 and 2014 with an age $\geq 18$. The median age of the whole population was 68 years old (mean \pm SD: $66.43 \pm 13.74$ ). We divided the patients into 11 age groups (every 5 years of age). Since the number of patients younger than 30 was small, we combined these patients into one group. If the median overall survival between two adjacent groups were significantly different, the youngest age of the latter group was set as the cut-off value (Table 1). Based on the cut-off points, all the patients were divided into 4 groups as follows: young age patients: $18-34$ years; middle-age patients: 35-64 years; elderly patients: 65-74 years; extremely elderly patients: $>74$ years. Young age patients accounted for 1.72\% (1369/79505) of all GC patients.

Table 1. Survival analysis among different age groups

\begin{tabular}{|c|c|c|c|c|c|c|}
\hline $\begin{array}{l}\text { Age } \\
\text { group }\end{array}$ & Age & $\begin{array}{l}\text { Number } \\
(\%)\end{array}$ & $\begin{array}{l}\text { Median } \\
\text { CSS } \\
\text { (Months) }\end{array}$ & $\begin{array}{l}\text { 5-year CSS } \\
\text { rate }(\%)\end{array}$ & $95 \%$ CI (\%) & $P$ value \\
\hline \multirow[t]{2}{*}{ Group 1} & $<30$ & $499(0.63)$ & 14 & 21.53 & $17.55-25.79$ & 0.0872 \\
\hline & $30-34$ & 870 (1.09) & 15 & 25.46 & $22.31-28.71$ & 0.0166 \\
\hline \multirow[t]{6}{*}{ Group 2} & $35-39$ & $\begin{array}{l}1539 \\
(1.94)\end{array}$ & 17 & 30.56 & $28.09-33.06$ & 0.3868 \\
\hline & $40-44$ & $\begin{array}{l}2623 \\
(3.30)\end{array}$ & 17 & 28.68 & $26.80-30.58$ & 0.3833 \\
\hline & $45-49$ & $\begin{array}{l}4097 \\
(5.15)\end{array}$ & 18 & 29.87 & 28.37-31.39 & 0.6340 \\
\hline & $50-54$ & $\begin{array}{l}6065 \\
(7.63)\end{array}$ & 18 & 28.75 & $27.51-30.01$ & 0.1731 \\
\hline & $55-59$ & $\begin{array}{l}7821 \\
(9.84)\end{array}$ & 19 & 29.49 & $28.39-30.61$ & 0.2634 \\
\hline & $60-64$ & $\begin{array}{l}9470 \\
(11.91)\end{array}$ & 19 & 29.27 & $28.26-30.29$ & 0.0086 \\
\hline \multirow[t]{2}{*}{ Group 3} & $65-69$ & $\begin{array}{l}10887 \\
(13.70)\end{array}$ & 19 & 31.75 & $30.80-32.72$ & 0.2732 \\
\hline & $70-74$ & $\begin{array}{l}11212 \\
(14.10)\end{array}$ & 20 & 31.37 & $30.43-32.32$ & 0.0071 \\
\hline Group 4 & $75+$ & $\begin{array}{l}24422 \\
(30.72)\end{array}$ & 16 & 27.34 & $26.70-27.98$ & \\
\hline
\end{tabular}

CSS: Cause specific survival, CI: Confidential Interval.

\section{Epidemiologic and clinicopathological characteristics}

General epidemiologic and clinicopathological characteristics among different age groups were summarized in Table 2. The proportion of young age patients had increased faster than the other 3 groups during the last decade. The proportion of female was significantly higher in young age group, compared to the middle-age and the elderly $(46.8 \%, 31.6 \%$ and $32.4 \%$, respectively. $\mathrm{P}<0.001)$. The ethnic composition and location of lesions were different between young age group and the other 3 groups (All $\mathrm{P}<0.001$ ). The diffuse type GC was much more common in the young age group $(47.6 \%)$ than in the other 3 age groups $(26.8 \%, 17.6 \%, 12.8 \%$, respectively, all $\mathrm{P}$ $<0.001)$. Besides, poorly differentiated tumors were remarkably more common in the young age group $(66.9 \%)$, and signet-ring cell carcinoma was more frequently seen in the young age patients (40.8\%). Moreover, less patients in the young age group received surgery $(45.4 \%)$ than the middle-age and the elderly groups $(\mathrm{P}<0.001)$, which was similar with the extremely elderly group. More young patients were diagnosed with distant metastasis $(28.1 \%)$ than the other 3 groups.

Table 2. Comparison of clinic-pathologic features among different age groups

\begin{tabular}{|c|c|c|c|c|c|}
\hline & $\begin{array}{l}<35(\%) \\
(\mathrm{N}=1369)\end{array}$ & $\begin{array}{l}35-64(\%) \\
(\mathrm{N}=31615)\end{array}$ & $\begin{array}{l}65-74(\%) \\
(\mathrm{N}=22099)\end{array}$ & $\begin{array}{l}>74(\%) \\
(\mathrm{N}=24422)\end{array}$ & $\begin{array}{l}P \\
\text { value }\end{array}$ \\
\hline \multicolumn{6}{|l|}{ Sex } \\
\hline Male & 728 (53.18) & $21618(68.38)$ & $\begin{array}{l}14935 \\
(67.58)\end{array}$ & $13169(53.92)$ & \\
\hline Female & $641(46.82)$ & 9997 (31.62) & 7164 (32.42) & $11253(46.08)$ & $<0.001$ \\
\hline \multicolumn{6}{|l|}{ Year } \\
\hline $1973-1983$ & $115(8.40)$ & 4295 (13.59) & $3292(14.90)$ & 3328 (13.63) & \\
\hline 1984-1993 & 175 (12.78) & 4305 (13.62) & $3826(13.71)$ & 3752 (15.36) & \\
\hline 1994-2003 & 399 (29.15) & 8145 (25.76) & $6118(27.68)$ & 7208 (29.51) & \\
\hline 2004-2014 & $680(49.67)$ & $14870(47.03)$ & $8863(40.11)$ & $10134(41.50)$ & $<0.001$ \\
\hline \multicolumn{6}{|l|}{ Lauren } \\
\hline Diffuse & $652(47.63)$ & $8473(26.80)$ & 3883 (17.57) & 3138 (12.85) & \\
\hline Intestinal & $668(48.79)$ & 21927 (69.36) & $\begin{array}{l}17330 \\
(78.42)\end{array}$ & $20469(83.81)$ & \\
\hline Unknown & $49(3.58)$ & $1215(3.84)$ & $886(4.01)$ & $815(3.34)$ & $<0.001$ \\
\hline \multicolumn{6}{|l|}{ Grade } \\
\hline Well & $31(2.26)$ & $1162(3.68)$ & $1117(5.05)$ & $1376(5.63)$ & \\
\hline Moderate & $123(8.98)$ & $6233(19.72)$ & $5363(24.27)$ & $6724(27.53)$ & \\
\hline Poorly & $916(66.91)$ & $17728(56.07)$ & $\begin{array}{l}11414 \\
(51.65)\end{array}$ & $11202(45.87)$ & \\
\hline Undifferentiated & $44(3.21)$ & $779(2.46)$ & $493(2.23)$ & $426(1.74)$ & \\
\hline Unknown & 255 (18.63) & 5713 (18.07) & $3712(16.80)$ & 4694 (19.22) & $<0.001$ \\
\hline \multicolumn{6}{|l|}{ Ethnicity } \\
\hline \multirow[t]{2}{*}{ Caucasian } & $888(64.86)$ & $22027(69.67)$ & $\begin{array}{l}15654 \\
(70.84)\end{array}$ & 17795 (72.86) & \\
\hline & $180(13.15)$ & $4306(13.62)$ & 2592 (11.73) & $2404(9.84)$ & \\
\hline \multicolumn{6}{|l|}{ African-American } \\
\hline Asian & 225 (16.44) & 4399 (13.91) & 3353 (15.17) & 3849 (15.76) & \\
\hline Others & $76(5.55)$ & $883(2.79)$ & $500(2.26)$ & $374(1.53)$ & $<0.001$ \\
\hline \multicolumn{6}{|l|}{ Primary site } \\
\hline Cardia & $295(21.55)$ & 10469 (33.11) & 6611 (29.92) & $5228(21.41)$ & \\
\hline Fundus & $43(3.14)$ & $1065(3.37)$ & $795(3.60)$ & 949 (3.89) & \\
\hline Body & $133(9.72)$ & $2165(6.85)$ & $1598(7.23)$ & $2019(8.27)$ & \\
\hline Antrum & 229 (16.73) & $5556(17.57)$ & 4471 (20.23) & $6026(24.67)$ & \\
\hline Pylorus & $46(3.36)$ & $987(3.12)$ & $764(3.46)$ & $982(4.02)$ & \\
\hline Lesser curvature & $121(8.84)$ & $2894(9.15)$ & $2225(10.07)$ & 2537 (10.39) & \\
\hline $\begin{array}{l}\text { Greater } \\
\text { curvature }\end{array}$ & $61(4.46)$ & $1234(3.90)$ & $906(4.10)$ & $1014(4.15)$ & \\
\hline Overlapping & 153 (11.18) & $2629(8.32)$ & $1728(7.82)$ & $1923(7.87)$ & \\
\hline NOS & $288(21.04)$ & $4616(14.60)$ & 3001 (13.58) & 3744 (15.33) & $<0.001$ \\
\hline \multicolumn{6}{|l|}{ Surgery } \\
\hline Yes & $720(52.60)$ & 19799 (62.63) & $\begin{array}{l}14516 \\
(65.69)\end{array}$ & $13149(53.84)$ & \\
\hline No & $621(45.36)$ & $11245(35.57)$ & $7112(32.18)$ & $10642(43.58)$ & \\
\hline Unknown & $28(2.05)$ & $571(1.81)$ & $471(2.13)$ & $631(2.58)$ & $<0.001$ \\
\hline \multicolumn{6}{|l|}{ Histology } \\
\hline Adenocarcinoma & $786(57.41)$ & $23721(75.03)$ & $\begin{array}{l}18372 \\
(83.13)\end{array}$ & $21403(87.64)$ & \\
\hline Signet Ring cell & $558(40.76)$ & $7169(22.68)$ & $3208(14.52)$ & 2548 (10.43) & \\
\hline
\end{tabular}




\begin{tabular}{|c|c|c|c|c|c|}
\hline $\begin{array}{l}\text { Mucinous } \\
\text { adenocarcinoma }\end{array}$ & $25(1.83)$ & 725 (2.29) & $519(2.35)$ & 471 (1.93) & $<0.001$ \\
\hline \multicolumn{6}{|l|}{ Tumor size (mm) } \\
\hline Median & 50 & 45 & 40 & 40 & \\
\hline Mean \pm SD & $158.0 \pm 300.3$ & $91.6 \pm 197.1$ & $71.9 \pm 156.7$ & $65.2 \pm 138.8$ & $<0.001$ \\
\hline \multicolumn{6}{|l|}{ AJCC $7^{\text {th }} \mathrm{T}$ stage } \\
\hline $\mathrm{T} 1$ & 119 (8.69) & 3011 (9.52) & 2194 (9.93) & $2951(12.08)$ & \\
\hline $\mathrm{T} 2$ & $42(3.07)$ & 1225 (3.87) & $863(3.91)$ & 967 (3.96) & \\
\hline $\mathrm{T} 3$ & $129(9.42)$ & $3545(11.21)$ & $2160(9.77)$ & $2020(8.27)$ & \\
\hline $\mathrm{T} 4$ & $222(16.22)$ & 4404 (13.93) & $2233(10.10)$ & $1987(8.14)$ & \\
\hline $\mathrm{Tx}$ & $857(62.60)$ & $19430(61.46)$ & $\begin{array}{l}14649 \\
(66.29)\end{array}$ & $16497(67.55)$ & $<0.001$ \\
\hline \multicolumn{6}{|l|}{ AJCC 7th $\mathrm{N}$ stage } \\
\hline No & $216(15.78)$ & $5273(16.68)$ & $3629(16.42)$ & 4851 (19.86) & \\
\hline N1 & $243(17.75)$ & 5511 (17.43) & 3114 (14.09) & $2773(11.35)$ & \\
\hline N2 & $64(4.67)$ & $1659(5.25)$ & $845(3.82)$ & $708(2.90)$ & \\
\hline N3 & $30(2.19)$ & $666(2.11)$ & $363(1.64)$ & $254(1.04)$ & \\
\hline $\mathrm{Nx}$ & $816(59.61)$ & $18506(58.54)$ & $\begin{array}{l}14148 \\
(64.02)\end{array}$ & $15836(64.84)$ & $<0.001$ \\
\hline \multicolumn{6}{|l|}{ AJCC $7^{\text {th }} \mathrm{M}$ stage } \\
\hline M0 & $276(20.16)$ & $9010(28.50)$ & $6184(27.98)$ & 7512 (30.76) & \\
\hline M1 & 385 (28.12) & $5452(17.24)$ & 2403 (10.87) & 1955 (8.01) & \\
\hline MX & 708 (51.72) & $17153(54.26)$ & $\begin{array}{l}13512 \\
(61.14)\end{array}$ & 14955 (61.24) & $<0.001$ \\
\hline \multicolumn{6}{|l|}{$\begin{array}{l}\text { AJCC 7th TNM } \\
\text { stage }\end{array}$} \\
\hline IA & $36(2.63)$ & $1290(4.08)$ & $1132(5.12)$ & 1364 (5.59) & \\
\hline IB & $15(1.10)$ & 755 (2.39) & $612(2.77)$ & $730(2.99)$ & \\
\hline IIA & $21(1.53)$ & $844(2.67)$ & $660(2.99)$ & $761(3.12)$ & \\
\hline IIB & $38(2.78)$ & $1531(4.84)$ & $999(4.52)$ & 987 (4.04) & \\
\hline IIIA & $51(3.73)$ & $1490(4.71)$ & $934(4.23)$ & 744 (3.05) & \\
\hline IIIB & $40(2.92)$ & 1207 (3.82) & $629(2.85)$ & $543(2.22)$ & \\
\hline IIIC & $28(2.05)$ & $710(2.25)$ & $434(1.96)$ & $320(1.31)$ & \\
\hline IV & 385 (28.12) & 5452 (17.24) & $2403(10.87)$ & 1955 (8.01) & \\
\hline Unknown & 755 (55.15) & $18336(58.00)$ & $\begin{array}{l}14296 \\
(64.69)\end{array}$ & 17018 (69.69) & $<0.001$ \\
\hline
\end{tabular}

NOS: Not otherwise specified; SD: Standard Deviation; AJCC: The American Joint Committee on Cancer; TNM: Tumor Node Metastasis

\section{Survival analysis}

The median CSS of the young age group was 12 months, which was significantly lower than the middle-age and the elderly groups (15 and 16 months, respectively, both $\mathrm{P}<0.001)$. The median overall survival between young age group and extremely elderly group was comparable (12 months vs. 13 months, $\mathrm{P}=0.153$ ) (Fig 1). To explore the prognostic factor for young age GC patients, we carried out the univariate and multivariate analysis in young GC group (Table 3). There were 952 deaths $(69.54 \%)$ in this group with a 5 -year CSS of $14.61 \% \quad(95 \% \mathrm{CI}$ : $12.80 \%-16.54 \%$ ).

Variables showing a trend for association with survival $(P<0.05)$ were selected in the cox proportional hazards model. Tumor location, ethnicity, tumor size $(\geq 5 \mathrm{~cm})$, surgery and TNM stage were identified as independent prognostic factors in young GC patients by both univariate and multivariate analysis.

\section{Validation using GC patients from SYSUCC}

We found that patients younger than 35 years old still had the worst prognosis among the four age groups (Figure 2). The median survival for these 4 groups patients were as follow: 25 months for patients younger than 35 years old, 57 months for patients who were 35-64 years, 43 months for patients who were 65-74 years and 38 months for patients $>74$ years old, $\mathrm{P}=0.0003$.

Table 3. Survival analysis for young patients with gastric cancer

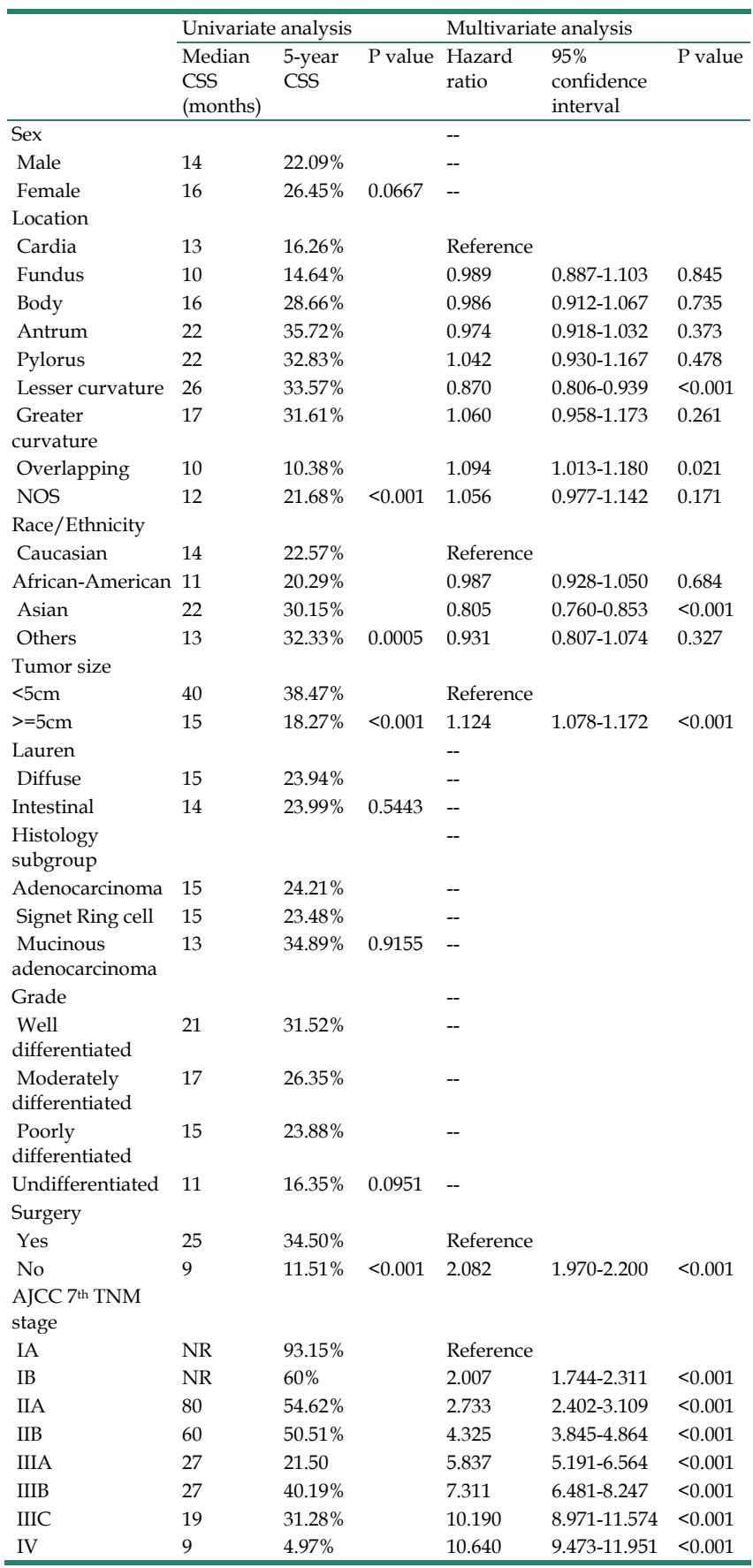

NOS: Not otherwise specified; CSS: Cause Specific Survival; AJCC: The American Joint Committee on Cancer; TNM: Tumor Node Metastasis

\section{Discussion}

The prognosis of GC in different age groups is still controversial. This may result from different definitions of young age. Most literatures defined 


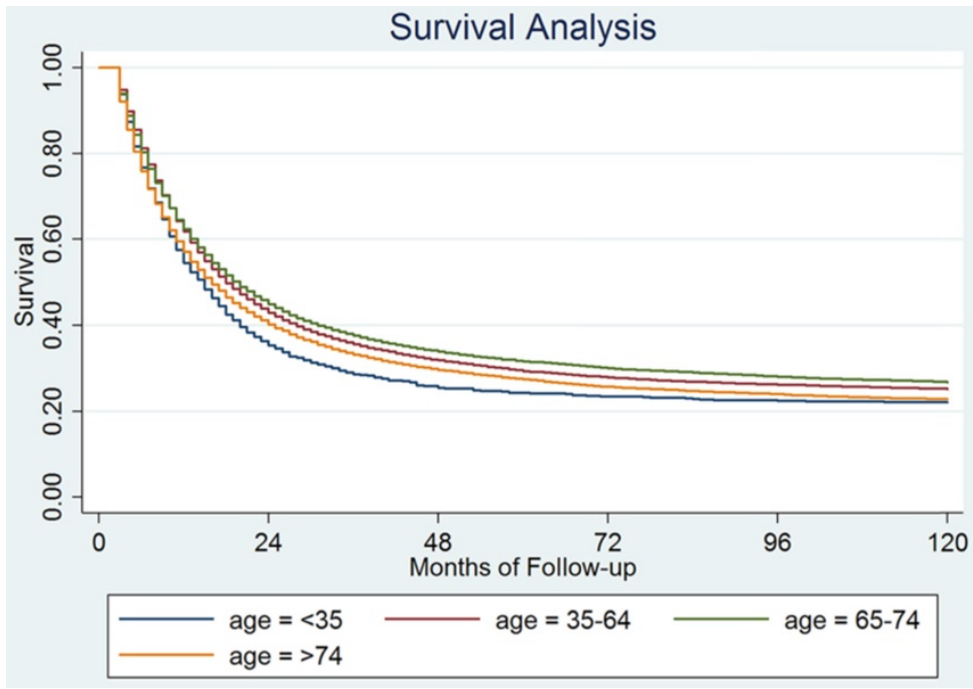

Figure 1. Cause specific survival among patients with different age groups from SEER data.

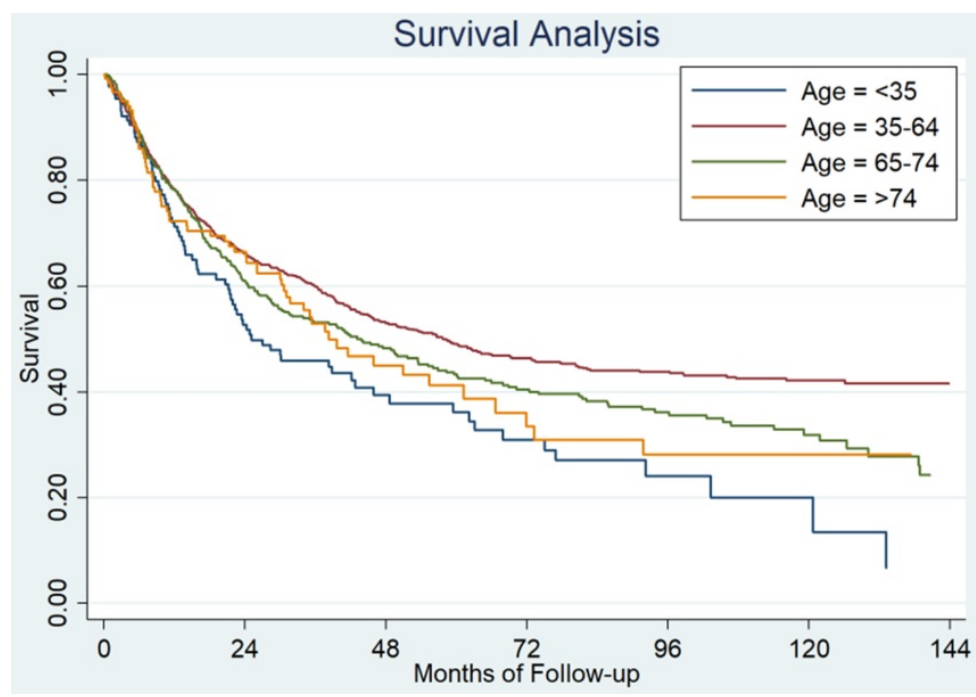

Figure 2. Cause specific survival among patients with different age groups from Sun Yat-sen University Cancer Center.

young age as below 40 or 45 years(5-7, 9, 12-19), while others used $30,50,60$ or even $70(4,8,10,11,20-23)$. Some studies simply used median age as the cutoff value to analyze the prognosis of age in GC patients (24-27). Most of the studies come to the conclusion that young patients had a better prognosis than elderly patients with the possible explanation that young patients had better performance status and better tolerance to therapy, while elderly patients might have more complication and could not stand effective therapy (10). In our clinical practice, we realized that young patients should be treated as two distinct types, pretty young patients who actually had worse prognosis than older patients and middle-age patients who had better prognosis. How can we figure out the young patients who have poor prognosis? In our study, we compared the survival of different groups GC patients according to their ages with an interval of 5 years. By combining patients with similar prognosis, we figured out 3 cutoff values, 35 years old, 65 years old and 75 years old. By this, we divided patients into 4 groups: young age patients: $18-34$ years; middle-age patients: 35-64 years; elderly patients: 65-74 years; extremely elderly patients: $>74$ years. Young patients had the worst prognosis, while the elderly group had the best prognosis. The median survivals for these two groups were 12months and 16months, respectively, $\mathrm{P}<0.001$. The poor prognosis for young patients remained valid in the SYSUCC database.

During the last few decades, the incidence of GC has declined in most countries. However, there is a rising trend in the incidence of GC in young age patients (2). Our study also showed that the proportion of young GC patients had increased in the last 4 decades. It has been suggested that GC in young patients has different clinical features and tumor behavior from older gastric cancer. Most common reported features by literatures included female dominance, location in upper third area, undifferentiated and diffuse histologic types, advanced stage at diagnosis $(5-7,9,10,15,23,28,29)$. In our study, the percentage of female patients in the young patient subgroup was higher than that in other age groups. The male-to-female ratio in the young age group was 1.14, in contrast to 2.16 in middle age group and 2.08 in elderly group. The reason for higher proportion of female in the young age group remains controversial. Sex hormone especially estrogen has been suggested to play a role in pathogenesis of GC $(14,30-33)$. Some studies reported the protective effect of estrogen in GC $(30,32,33)$, while others claimed the opposite $(14,31)$. Chung et.al suggested that the excessive exposure of estrogen without the counter effect of progesterone may increase the risk of GC (14). Further studies are needed to clarify the underlying mechanism of female dominance in young age GC patients.

Regarding histologic classifications, previous studies have showed poor-differentiated or undifferentiated and diffuse-type gastric cancer predominated in young age patients $(7,9,14,15,23$, 34 ). Our study also showed a higher proportion of diffuse type and poor differentiated gastric cancer in the young age group. Previous studies indicated that intestinal-type and well differentiated GC originates from intestinal metaplasia or atrophic gastritis, which is associated with infection by Helicobacter pylori. This 
progression from infection of H.pylori to pre-malignant stage and finally malignant tumor may take many years (35-37). However, the diffuse-type adenocarcinoma or poor-differentiated gastric cancer may develop without passing all these stages. Young age patients have fewer years to pass through these stages, which may partially explain why diffuse-type and poor-differentiated is more common in the young age group. Moreover, it has been reported that diffuse type GC is associated with E-cadherin deregulation upon genetic alterations (38), and E-cadherin gene (CDH1) mutations are more common in young age GC (39). According to the definition of hereditary diffuse gastric cancer, diffuse gastric cancer patients who are younger than 40 years old have met the criteria (40). Hence the genetic factors may play an important role in the development of GC in young age patients.

To explore the factors that contribute to the worse survival in pretty young GC patients, we carried out the univariate and multivariate analysis. We found that location of tumor, ethnicity, tumor size, surgery and TNM stage were independent risk factors in young age patients. Previous studies have suggested various clinicopathological factors, including tumor location, tumor size, depth of invasion, lymphovascular invasion, peritoneal metastasis, distant metastasis, curative resection, CEA and CA125 level, and TNM stage (5-7, 10, 14, 17-19, 23, $34,41)$. Curative resection was the most common risk factor seen in these studies. Several studies found that the prognosis of young age patients after curative surgery was comparable or better than the old age patients $(5,23,41,42)$, and prognosis of advanced stages was worst in young age patients than the old age patients $(29,43)$. However, few young age patients present with alarm symptoms and they do not receive regular screen by gastroscopy. More patients in young age group were diagnosed at stage IV and lost the chance for curative resection. Considering genetic factors may play a role in development of early gastric cancer, it is reasonable to offer earlier screening to young people with family history. Further studies are warranted to figure out the high risk factor for gastric cancer and based on these to design the screen strategy in high risk young people. It is also important to find out more effective screen methods, such as liquid biopsy or superfine gastroscopy.

There were some limitations to this study. Firstly, it was a retrospective study. Secondly, as this study overlapped long time frame and AJCC staging system for gastric cancer changed, the current study couldn't reflect the stages and clinical practice of gastric cancer in previous years. Thirdly, the SEER database does not include data on signs and symptoms, family history, level of tumor markers, chemotherapy, and other factors that might affect prognosis. Further studies are needed to elucidate the mechanism for poor prognosis of young age patients.

\section{Conclusion}

This study demonstrated that gastric cancer patients $<35$ years old had a poor prognosis. Location of tumor, ethnicity, tumor size, surgery and TNM stage were independent risk factors on prognosis for young patients. Early detection of gastric cancer is very important in all patients but in young patients it is of paramount importance.

\section{Supplementary Material}

Supplementary table.

http://www.jcancer.org/v10p0472s1.pdf

\section{Acknowledgments}

We would like to thank the staff members of the National Cancer Institute and their colleagues across the United States and at Information Management Services, Inc., who have been involved with the Surveillance, Epidemiology and End Results (SEER) Program.

\section{Funding}

This work was supported by National Natural Science Foundation of China (Grant number. 81602066 and 81772587); the Fundamental Research Funds for the Central Universities (Grant number. 16ykpy25); the third outstanding young talents training plan and Medical Scientist program of Sun Yat-sen University cancer center; Science and Technology Planning Project of Guangzhou, China (Grant number. 201510161726583); National Science and Technology Major Project, China (Grant number. 2016ZX09101004).

\section{Competing Interests}

The authors have declared that no competing interest exists.

\section{References}

1. Torre LA, Bray F, Siegel RL, Ferlay J, Lortet-Tieulent J, Jemal A. Global cancer statistics, 2012. CA Cancer J Clin. 2015;65:87-108.

2. Camargo MC, Anderson WF, King JB, Correa P, Thomas CC, Rosenberg PS, et al. Divergent trends for gastric cancer incidence by anatomical subsite in US adults. Gut. 2011;60:1644-9.

3. Anderson WF, Camargo MC, Fraumeni JF, Jr., Correa P, Rosenberg PS, Rabkin CS. Age-specific trends in incidence of noncardia gastric cancer in US adults. JAMA. 2010;303:1723-8.

4. Suh DD, Oh ST, Yook JH, Kim BS, Kim BS. Differences in the prognosis of early gastric cancer according to sex and age. Therap Adv Gastroenterol. 2017;10:219-29.

5. Isobe T, Hashimoto K, Kizaki J, Miyagi M, Aoyagi K, Koufuji K, et al. Characteristics and prognosis of gastric cancer in young patients. Oncol Rep. 2013;30:43-9. 
6. Saito H, Takaya S, Fukumoto Y, Osaki T, Tatebe S, Ikeguchi M. Clinicopathologic characteristics and prognosis of gastric cancer in young patients. Yonago Acta Med. 2012;55:57-61.

7. Liu S, Feng F, Xu G, Liu Z, Tian Y, Guo M, et al. Clinicopathological features and prognosis of gastric cancer in young patients. BMC Cancer. 2016;16:478.

8. Pisanu A, Podda M, Cois A, Uccheddu A. Gastric cancer in the young: is it a different clinical entity? A retrospective cohort study. Gastroenterol Res Pract. 2014;2014:125038

9. Takatsu Y, Hiki N, Nunobe S, Ohashi M, Honda M, Yamaguchi T, et al. Clinicopathological features of gastric cancer in young patients. Gastric Cancer. 2016;19:472-8.

10. Qiu MZ, Wang ZQ, Zhang DS, Luo HY, Zhou ZW, Wang FH, et al. Clinicopathological characteristics and prognostic analysis of gastric cancer in the young adult in China. Tumour Biol. 2011;32:509-14.

11. Al-Refaie WB, Hu CY, Pisters PW, Chang GJ. Gastric adenocarcinoma in young patients: a population-based appraisal. Ann Surg Oncol. 2011;18:2800-7.

12. Li H, Liu Z, Xu C, Chen Y, Zhang J, Cui B, et al. Overexpression of S100A4 is closely associated with the progression and prognosis of gastric cancer in young patients. Oncol Lett. 2013;5:1485-90.

13. Dhobi MA, Wani KA, Parray FQ, Wani RA, Wani ML, Peer GQ, et al. Gastric cancer in young patients. Int J Surg Oncol. 2013;2013:981654.

14. Chung HW, Noh SH, Lim JB. Analysis of demographic characteristics in 3242 young age gastric cancer patients in Korea. World J Gastroenterol. 2010;16:256-63.

15. Park JC, Lee YC, Kim JH, Kim YJ, Lee SK, Hyung WJ, et al. Clinicopathological aspects and prognostic value with respect to age: an analysis of 3,362 consecutive gastric cancer patients. J Surg Oncol. 2009;99:395-401.

16. Lee J, Lee MA, Kim IH, Roh SY. Clinical characteristics of young-age onset gastric cancer in Korea. BMC Gastroenterol. 2016;16:110.

17. Santoro R, Carboni F, Lepiane P, Ettorre GM, Santoro E. Clinicopathological features and prognosis of gastric cancer in young European adults. Br J Surg. 2007:94:737-42.

18. Kulig J, Popiela T, Kolodziejczyk P, Sierzega M, Jedrys J, Szczepanik AM, et al. Clinicopathological profile and long-term outcome in young adults with gastric cancer: multicenter evaluation of 214 patients. Langenbecks Arch Surg. 2008;393:37-43.

19. Llanos O, Butte JM, Crovari F, Duarte I, Guzman S. Survival of young patients after gastrectomy for gastric cancer. World J Surg. 2006;30:17-20.

20. Merchant SJ, Kim J, Choi AH, Sun V, Chao J, Nelson R. A rising trend in the incidence of advanced gastric cancer in young Hispanic men. Gastric Cancer. 2017;20:226-34.

21. Lopez-Basave HN, Morales-Vasquez F, Ruiz-Molina JM, Namendys-Silva SA, Vela-Sarmiento I, Ruan JM, et al. Gastric cancer in young people under 30 years of age: worse prognosis, or delay in diagnosis? Cancer Manag Res. 2013:5:31-6.

22. Nelen SD, Verhoeven RHA, Lemmens V, de Wilt JHW, Bosscha K. Increasing survival gap between young and elderly gastric cancer patients. Gastric Cancer. 2017;20:919-28.

23. Park HJ, Ahn JY, Jung HY, Lim H, Lee JH, Choi KS, et al. Clinical characteristics and outcomes for gastric cancer patients aged 18-30 years. Gastric Cancer. 2014;17:649-60.

24. Qiu MZ, Qiu HJ, Wang ZQ, Ren C, Wang DS, Zhang DS, et al. The tumor-log odds of positive lymph nodes-metastasis staging system, a promising new staging system for gastric cancer after D2 resection in China. PLoS One. 2012;7:e31736.

25. Qiu MZ, Wang ZQ, Luo HY, Zhang DS, Zhou ZW, Li YH, et al. Prognostic analysis in node-negative gastric cancer patients in China. Tumour Biol. 2011;32:489-92.

26. Qiu MZ, Cai MY, Zhang DS, Wang ZQ, Wang DS, Li YH, et al. Clinicopathological characteristics and prognostic analysis of Lauren classification in gastric adenocarcinoma in China. J Transl Med. 2013;11:58

27. Qiu MZ, Wang ZQ, Zhang DS, Liu Q, Luo HY, Zhou ZW, et al. Comparison of 6th and 7th AJCC TNM staging classification for carcinoma of the stomach in China. Ann Surg Oncol. 2011;18:1869-76.

28. Seker M, Aksoy S, Ozdemir NY, Uncu D, Zengin N. Clinicopathologic features of gastric cancer in young patients. Saudi J Gastroenterol. 2013;19:258-61.

29. Tavares A, Gandra A, Viveiros F, Cidade C, Maciel J. Analysis of clinicopathologic characteristics and prognosis of gastric cancer in young and older patients. Pathol Oncol Res. 2013;19:111-7.

30. Frise S, Kreiger N, Gallinger S, Tomlinson G, Cotterchio M. Menstrual and reproductive risk factors and risk for gastric adenocarcinoma in women: findings from the canadian national enhanced cancer surveillance system. Ann Epidemiol. 2006;16:908-16.

31. Heuch I, Kvale G. Menstrual and reproductive factors and risk of gastric cancer: a Norwegian cohort study. Cancer Causes Control. 2000;11:869-74.

32. La Vecchia C, D'Avanzo B, Franceschi S, Negri E, Parazzini F, Decarli A. Menstrual and reproductive factors and gastric-cancer risk in women. Int J Cancer. 1994;59:761-4.

33. Duell EJ, Travier N, Lujan-Barroso L, Boutron-Ruault MC, Clavel-Chapelon F, Palli D, et al. Menstrual and reproductive factors, exogenous hormone use, and gastric cancer risk in a cohort of women from the European Prospective Investigation Into Cancer and Nutrition. Am J Epidemiol. 2010;172:1384-93.

34. Strong VE, Russo A, Yoon SS, Brennan MF, Coit DG, Zheng $\mathrm{CH}$, et al. Comparison of Young Patients with Gastric Cancer in the United States and China. Ann Surg Oncol. 2017;24:3964-71.
35. Milne AN, Offerhaus GJ. Early-onset gastric cancer: Learning lessons from the young. World J Gastrointest Oncol. 2010;2:59-64.

36. Peleteiro B, Lopes C, Figueiredo C, Lunet N. Salt intake and gastric cancer risk according to Helicobacter pylori infection, smoking, tumour site and histological type. Br J Cancer. 2011;104:198-207.

37. Canedo P, Figueiredo C, Machado JC. After Helicobacter pylori, genetic susceptibility to gastric carcinoma revisited. Helicobacter. 2007;12 Suppl 2:45-9.

38. Paredes J, Figueiredo J, Albergaria A, Oliveira P, Carvalho J, Ribeiro AS, et al. Epithelial E- and P-cadherins: role and clinical significance in cancer. Biochim Biophys Acta. 2012;1826:297-311.

39. Corso G, Pedrazzani C, Pinheiro H, Fernandes E, Marrelli D, Rinnovati A, et al. E-cadherin genetic screening and clinico-pathologic characteristics of early onset gastric cancer. Eur J Cancer. 2011;47:631-9.

40. van der Post RS, Vogelaar IP, Carneiro F, Guilford P, Huntsman D, Hoogerbrugge $\mathrm{N}$, et al. Hereditary diffuse gastric cancer: updated clinical guidelines with an emphasis on germline CDH1 mutation carriers. J Med Genet. 2015:52:361-74.

41. Kim DY, Ryu SY, Kim YJ, Kim SK. Clinicopathological characteristics of gastric carcinoma in young patients. Langenbecks Arch Surg. 2003;388:245-9.

42. Bai Y, Li ZS. Endoscopic, clinicopathological features and prognosis of very young patients with gastric cancer. J Gastroenterol Hepatol. 2011;26:1626-9.

43. Nakamura R, Saikawa Y, Takahashi T, Takeuchi H, Asanuma H, Yamada Y, et al. Retrospective analysis of prognostic outcome of gastric cancer in young patients. Int J Clin Oncol. 2011;16:328-34. 